\title{
Development of Low Carbon Cities: Assessment of Carbon Dioxide Emissions from Energy Facilities in Irkutsk City
}

\author{
E.P. Maysyuk ${ }^{*}$
}

Melentiev Energy Systems Institute of Siberian Branch of Russian Academy of Sciences, Irkutsk, Russia

\begin{abstract}
Decrease in greenhouse gas emissions is a current trend in solving the climate change problems. The concept of low-carbon cities is extensively discussed nowadays. It aims to reduce greenhouse gas emissions through integrated mechanisms and measures, which comply with socio-economic development and city management. Since a considerable part of the population lives in cities, the utmost goal of the study is to analyze the situation with emissions of the main greenhouse gas, i.e., carbon dioxide, in the urban environment. The major sources of carbon dioxide emissions are stationary energy facilities of different capacities burning fuel. The paper considers the city of Irkutsk as an example of the populated area included in the study on low carbon cities under the auspices of the Social and Economic Commission for Asia and the Pacific of the UN - UNESCAP. The first stage of the studies involved assessing the current carbon dioxide emissions from energy facilities of the city through the calculation of carbon dioxide emissions from boiler houses and the city cogeneration plant for 1990. The findings revealed the potential of reducing carbon dioxide emissions from energy facilities in Irkutsk. The paper suggests the basic directions and measures to mitigate greenhouse gas emissions from the urban energy facilities.
\end{abstract}

Index Terms: Climate change, International agreements, greenhouse gas emissions, the city of Irkutsk, boiler houses, the Novo-Irkutsk cogeneration plant.

\footnotetext{
${ }^{*}$ Corresponding author.

E-mail: maysyuk@isem.irk.ru
}

http://dx.doi.org/10.38028/esr.2021.01.0002

Received March 01, 2021. Revised March 09, 2021

Accepted March 15, 2021. Available online May 26, 2021.

This is an open access article under a Creative Commons Attribution-NonCommercial 4.0 International License.

C) 2021 ESI SB RAS and authors. All rights reserved.

\section{INTRODUCTION}

At present, the world community raises an issue on the role of cities as the major sources of greenhouse gas emissions increasingly more often. In 2011, the UN Economic Commission published the report "Climatically neutral cities" [1], which analyzed the role of cities and their effect on climate change. The bulk of the population resides in cities concentrating on business activity, social and intellectual life. Therefore, the urban environment possesses the greatest resources to decrease energy intensity and energy consumption and thus mitigate greenhouse gas emissions. The concept of low carbon cities suggests not only a direct cutdown in emissions but also the design of mechanisms and complex measures that are integrated within the city and aimed at making coordinated decisions on the reduction of carbon dioxide emissions.

The idea of low carbon cities was supported by the Social and Economic Commission for Asia and the Pacific of the UN (UNESCAP). The Commission is developing some programs on environmental cooperation in Northeast Asia. The platform on the low carbon cities in Northeast Asia - NEALCCP (Northeast Asia Low Carbon City Platform) operates under the auspices of UNESCAP. The platform aims to involve different stakeholders in climate protection and the development of low carbon cities, i.e., cities with a low level of carbon dioxide emissions. The twenty-third panel of UNESCAP in October 2019 supported the proposal put forward by Mongolia and the Russian Federation to expand the activities and incorporate the Mongolian (Chingis, Tsetserleg) and the Russian (UlanUde and Irkutsk) cities in the study on the development of low carbon cities.

The development of comprehensive measures on the mitigation of carbon dioxide emissions in the cities requires, first of all, an analysis of the current general state of the settlement (population, economy, climate, transport, and energy infrastructure), and also the ecological state.

This study considers the energy sector as one of the chief sectors of the economy in Irkutsk. The paper 
presents an assessment of carbon dioxide emissions caused by the operation of energy facilities.

\section{LITERATURE REVIEW}

The world community has been discussing the issues of greenhouse gas emissions for long. The first reliable information on changes in climate and possible causes of its fluctuations appeared as far back as the 19th century [2], and the relation between these changes and the higher carbon dioxide concentration is validated by numerous studies [3-5].

However, the debates concerning the effect of greenhouse gases on climate both locally and globally are still going on. Of special concern is the human contribution to the accelerated warming in the last decades. The opinions of scientists on this issue vary. Some of them discuss the theories of natural cyclical changes caused by the release of space and solar plasma [6,7], while others lay the stress on the anthropogenic effects due to human activity and increase in carbon dioxide emissions as a result of growing business activity $[8,9]$.

Recent decades have seen new records of the climatic changes, the mean temperatures rise, and the distribution of atmospheric precipitation changes. The area of glaciers, ice sheets, and arctic seawater ices shrinks faster than it was forecasted. The most significant climate change consequences both observed and forecasted were revealed in all European regions. Accordingly, the climate change consequences for seas are related to the rise in water temperature and acidity. In the coastal zones, the sea level rose, the shorelines eroded, the storms became more frequent and severe [10]. It is expected that in the future, there will be more intensive and numerous climate changes. Even if the greenhouse gas emissions were completely stopped now, the climate would continue to change for many decades because of earlier releases and inertia of the climatic system [10].

At present, the planet climate conservation issue is the focus of attention of practically all world's countries. The UN Framework Convention on Climate Change (UN FCCC) reflected the interest of the international community in decreasing greenhouse gas emissions in 1992. The goal of the Convention was to stabilize the greenhouse gas concentrations in the atmosphere at a level, which would prevent dangerous man-induced impact on the climatic system [11]. This Convention was signed by 197 countries, including those of the former USSR and all industrially developed countries. Later, in 1997, the Framework Convention was supplemented by the Kyoto Protocol that fostered the development of the provisions of the UN FCCC, calling for the developed countries to limit and cut down greenhouse gas emissions under the agreed national commitments. The Protocol was adopted since the Convention of 1992 contained only the calls to these countries to pursue a policy and take measures to prevent climate change. The Kyoto Protocol establishes specific emission reduction commitments for industrially developed countries, including the European countries. Generally, these commitments correspond to approximately a five-percent decrease in emissions against the 2012 levels [12]. With the complex process of the Kyoto Protocol ratification and the need to solve the problems of climate change, in 2015, the world community once again adopted the worldwide document, the so-called Paris Climate Agreement [13]. It formulates the issues of greenhouse gas emission mitigation somewhat differently. The Agreement suggested limiting global warming, providing temperature change by no more than $2^{\circ} \mathrm{C}$ by 2050 , and preferably $1.5^{\circ} \mathrm{C}$ by 2040 with further zero (zeroing) growth of the global temperature on the planet. Essentially, it declared a transition to carbon-free technologies.

It is worth noting that many world's countries are affiliated with this process. The Paris Agreement was signed by 196 countries of the world, including Russia, China, Mongolia, Japan, European countries, and others. At the beginning of 2021, the USA also signed this Agreement.

The Russian Federation confirmed its commitment to the Paris Agreement (as of 2015) by the Russian Government Decree of September 21, 2019, and became an authorized participant in this international-legal instrument. In 2014, before signing the Agreement, Russia developed an Action Plan to ensure a reduction in greenhouse gas emissions by 2020 to a level of no more than $75 \%$ of the 1990 level (approved by the Decree of the Government of the Russian Federation of April 2, 2014, No. 504-r). And every five years, the Russian Federation undertakes to submit a report on Russia's contribution to the reduction of anthropogenic greenhouse gas emissions to the Secretariat of the UN Framework Convention on Climate Change. The Russian Federation adopted the Orders and Decrees (2014, 2015) on the inventory of greenhouse gas emissions, developed the guidelines for assessing emissions for various types of economic activities. In 2020, the Ministry of Economic Development of Russia prepared a draft long-term strategy for the development of the Russian Federation with a low level of greenhouse gas emissions until 2050 (March 2020).

The Asia-Pacific region countries also seek to transition to carbon-free technologies in their energy development [14]. The primary technologies aimed at achieving a climate-neutral world (zeroing emissions by 2050) include the use of renewable energy sources instead of coal for energy purposes; the involvement of electric transport (electric vehicles) with additional preferences in its operation; promotion of studies on the development of hydrogen technologies; bans on deforestation, and others.

The main focus is, of course, on the transformation of the energy sector, i.e., a change in the fuel and energy balance structure; energy conservation; an introduction of innovative technologies and intelligent systems for energy consumption and production; use of renewable energy resources, including hydro resources; industrial energy disposal, and others. 
Table 1 . The values of potentials of global warming caused by greenhouse gases.

\begin{tabular}{|c|c|c|c|}
\hline Greenhouse gas & Chemical formula & $\begin{array}{c}\text { Potential of global } \\
\text { warming, } \mathrm{t} \mathrm{CO}_{2} \text {-equiv./t }\end{array}$ & Production process \\
\hline Carbon dioxide & $\mathrm{CO}_{2}$ & 1 & $\begin{array}{l}\text { Stationary fuel combustion, flaring, fugitive emissions, } \\
\text { oil refining. Production: coke, concrete, lime, glass, } \\
\text { ceramic wares, ammonia, ferroalloys, primary } \\
\text { aluminum. Petrochemistry, ferrous industry, air, railway } \\
\text { transport, and other industrial processes. }\end{array}$ \\
\hline Methane & $\mathrm{CH}_{4}$ & 25 & Flaring, fugitive emissions \\
\hline Nitrogen oxide & $\mathrm{N}_{2} \mathrm{O}$ & 298 & $\begin{array}{l}\text { Production of nitric acid, caprolactam, glyoxal, and } \\
\text { glyoxalic acid. }\end{array}$ \\
\hline Fluoroform & $\mathrm{CHF}_{3}$ & 14800 & Production of fluorine-containing compounds. \\
\hline Perfluoromethane & $\mathrm{CF}_{4}$ & 7390 & Production of primary aluminum. \\
\hline Perfluoroethane & $\mathrm{C}_{2} \mathrm{~F}_{6}$ & 12200 & Production of primary aluminum. \\
\hline Sulfur hexafluoride & $\mathrm{SF}_{6}$ & 22800 & Production of fluorine-containing compounds \\
\hline
\end{tabular}

Since it is rather difficult to stop using fossil fuel in the near future, the world community has proposed developing commercially viable clean coal technologies with $100 \%$ of $\mathrm{CO}_{2}$ capture as soon as possible. Carbon capture and storage technology allows capturing waste carbon dioxide from flue gases of power plants based on the methods of absorption, adsorption, membrane gas separation, and others [15]. Experts claim that technically the capture and storage of large amounts of $\mathrm{CO}_{2}$ will not pose a big problem. Moreover, the widespread use of these technologies can significantly contribute to the achievement of the ambitious climate targets set by the Paris Agreement.

In 2019, the world had 17 carbon disposal projects aimed at capturing up to 31.5 million tons of $\mathrm{CO}_{2}$ per year, with 3.7 million tons stored in geological structures [16].

At the initiative of the Global Energy Association for the development of international research and projects in the field of energy and with the direct participation of the world expert community representatives, breakthrough energy technologies have been developed to minimize or avoid carbon dioxide emissions [17].

The technologies for mitigation of greenhouse gas emissions also include new technologies for energy production and conversion, which involve creating closed thermodynamic cycles with zero emissions [18]. Specific features and advantages of such technologies are oxygen fuel combustion accompanied by the production of water vapor and carbon dioxide with the condensation of the latter, its capture, and transportation to the storage site.

The efficient use of resources and the creation of a low carbon society are the focus of the world's discussions on the transition to the "green" economy, which is reflected in the mid-and long-term plans of Europe's development [19]. The Action Plan for the transition to the low carbon economy suggests that the emissions of the European community must be decreased by $80 \%$ by 2050 against the 1990 level based on the internal mitigations.

Thus, to date, a global opinion has been formed, which is supported and authorized by the relevant documents aimed at reducing greenhouse gas emissions and using carbon-free or low carbon technologies for the vital activities of the planet's population.

\section{The Methodology of InVestigation}

Since June 2015, the Order of the Ministry of Natural Resources of the Russian Federation No. 300 has been in effect in Russia, which approves methodological guidelines and guidance for quantifying the greenhouse gas emissions by organizations engaged in various economic activities [20]. These guidelines are based on the Action Plan to decrease greenhouse gas emissions by 2020, which was approved by Order No. 504-r of the Government of the Russian Federation dated April 2, 2014. The main goal of the Plan is to ensure that by 2020 Russia's greenhouse gas emissions do not exceed $75 \%$ of the 1990 emissions [21].

The methodological guidelines establish a procedure for quantifying greenhouse gas emissions for their monitoring, reporting, and verifying. Since 2017, all enterprises with emissions of more than 50 thousand tons of $\mathrm{CO}_{2}$-equiv. per year must report on greenhouse gas emissions.

The developed Greenhouse Gas Inventory Methods are based on the international recommendations, are approved by the Ministry of Natural Resources of the Russian Federation, and include all categories of sources and sinks of greenhouse gases.

In general, seven gaseous compounds, which cause the so-called greenhouse effect, i.e., upset the planet's heat exchange, are classified as greenhouse gases (Table 1). The data on the global warming potential for the selected greenhouse gases were developed following Decision 24 / SR.19 of the Conference of the Parties engaged in the UN Framework Convention on Climate Change, ratified by Federal Law No. 34 of 04.11.1994 "On Ratification of the UN Framework Convention on Climate Change" $[22,23]$. The gases indicated in the Table have different warming potential: carbon dioxide has the lowest potential, and sulfur hexafluoride (released during the production of fluorine-containing compounds) has the highest potential.

Among different production processes, energy facilities and especially fossil fuel combustion cause the greatest emissions of greenhouse gases and primarily $\mathrm{CO}_{2}$.

The greenhouse gas emissions are determined quantitatively by different methods designed for corresponding categories of their sources: 


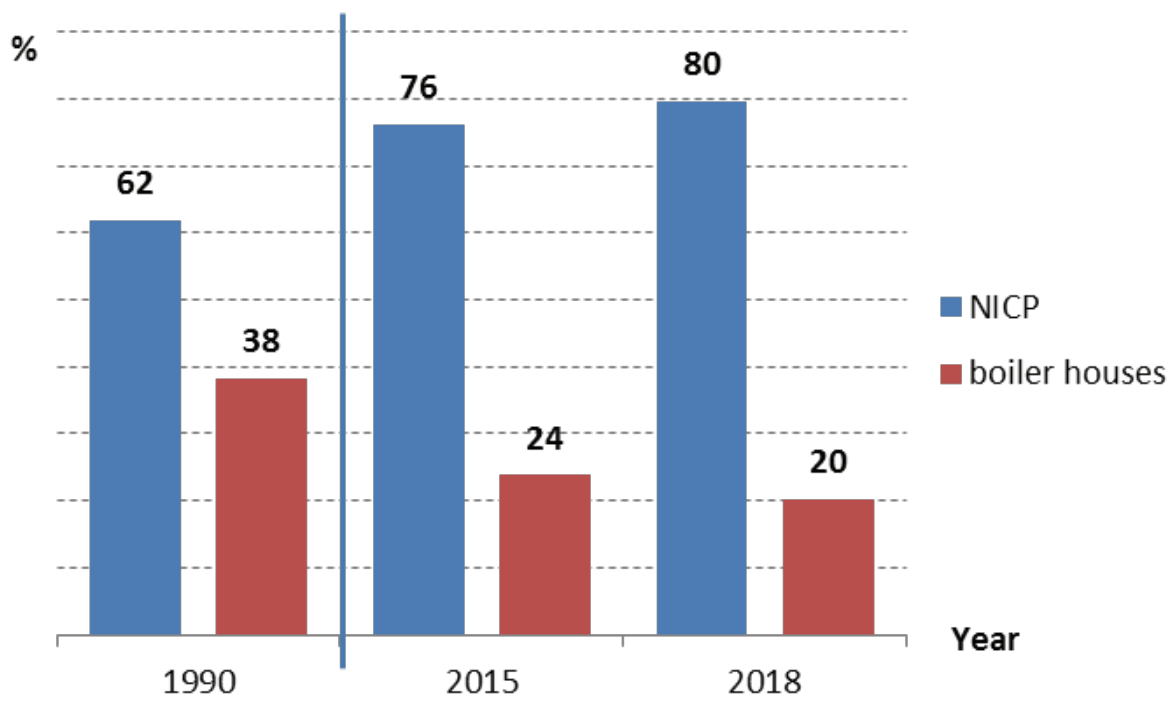

Fig. 1. Dynamics of fuel consumption structure by energy facilities in the city of Irkutsk.

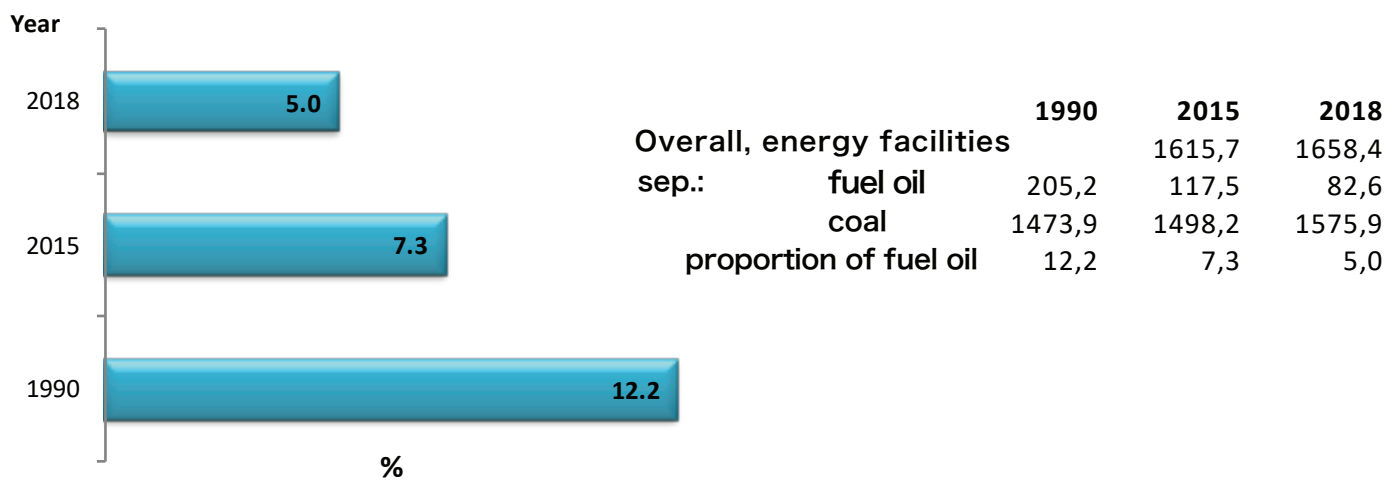

Fig. 2. Dynamics and share of fuel oil in fuel consumption structure for energy facilities in the city of Irkutsk.

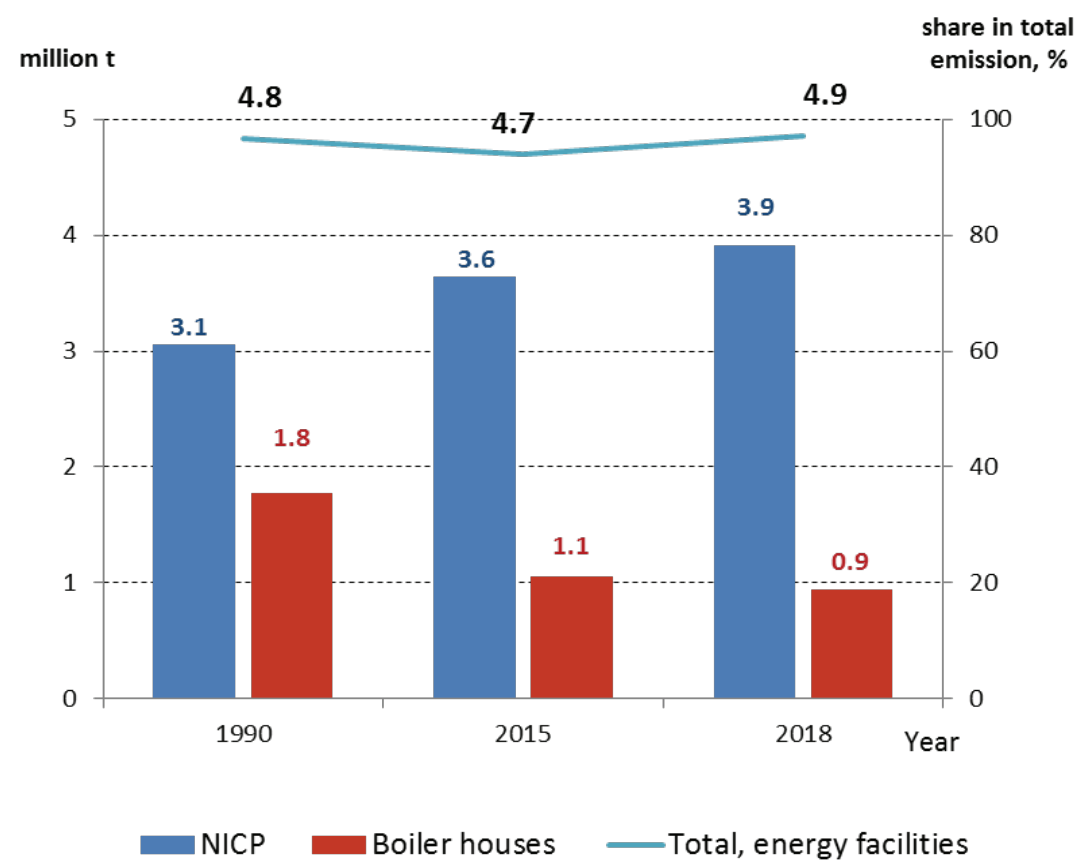

Fig. 3. Dynamics of emissions and assessment of the contribution of energy facilities to the total $\mathrm{CO}_{2}$ emission in Irkutsk city in 1990, 2015 and 2018. 
Table 2. Dynamics of fuel consumption by type in irkutsk, thousand tce.

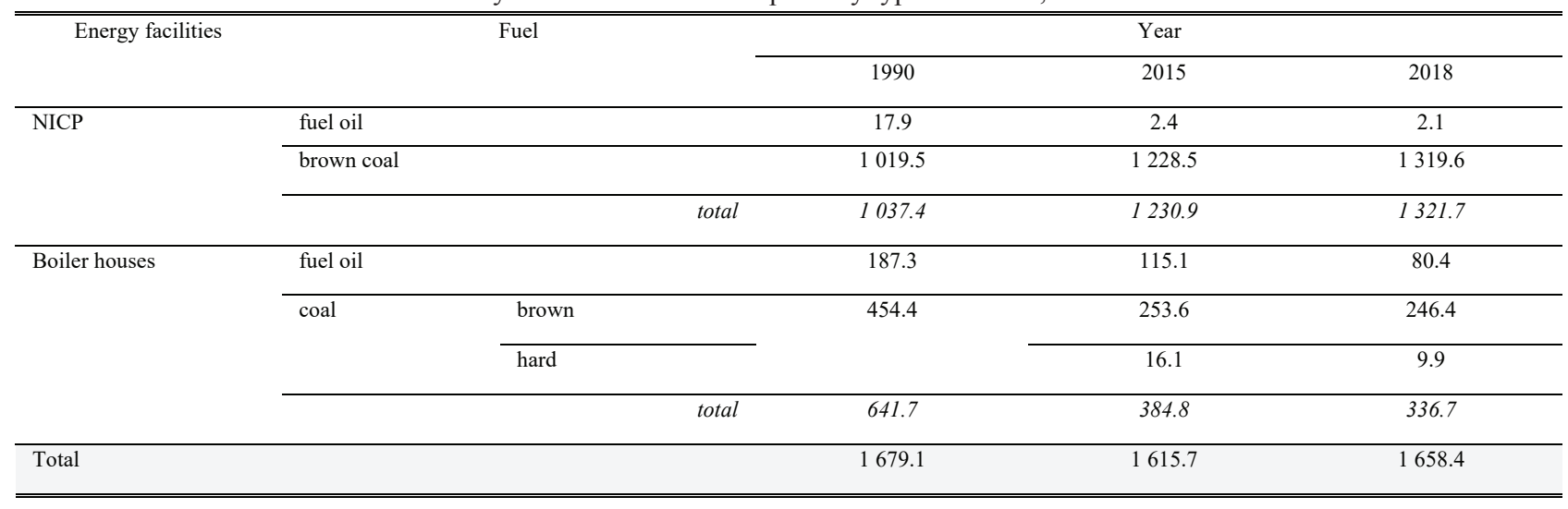

- the calculation method based on the periodic measurements of emissions;

- the method of the continuous monitoring of greenhouse gas emissions;

- the calculation method based on material balance;

- the calculation method based on the data on the enterprise performance and the emission factors.

The calculation methods relying on periodic measurements and continuous monitoring of greenhouse gas emissions employ the results of instrumental measurements at the enterprises for a period (year) at issue. These results are given in the protocols of measurements, technical specifications, reports of inventory checks of emission sources, data on in-process control of emissions and production of waste, and others. The rate of data logging and the methods of their averaging are chosen by the organization individually so as to provide their objectivity for the considered period.

Calculation based on the material balance assumes the use of data from the accounting documents on the consumption of raw materials, fuel, and materials; production of products (for example, technical reports, balances, statistical reporting forms, and others); quality certificates, and other sources of information. The calculation takes into account changes in the reserves of resources at the enterprise [20].

The input data for the greenhouse gas emission calculation by the method based on the data on enterprise performance and emission factors are the actual data, which characterize the enterprise activity for the sample period (for example, fuel consumption by type, consumption of carbon-containing materials), greenhouse gas emission factors, calculated factors of carbon content in fuel, and component composition for gaseous fuel.

This study relies on the methodological guidelines [20] for the category of stationary fuel combustion to estimate the greenhouse gas emissions from energy enterprises generating electric and thermal energy. At the same time, only carbon dioxide $\left(\mathrm{CO}_{2}\right)$ emissions are classified as greenhouse gas emissions subject to mandatory accounting (in this category of emission sources).

\section{RESULTS}

The primary energy facilities for electricity and heat supply to the population and industrial enterprises of Irkutsk are boiler houses of different capacities, the Irkutsk HPP, and one large thermal power plant, i.e., the Novo-Irkutsk cogeneration plant (NICP). The installed capacity of the Irkutsk HPP is $662.4 \mathrm{MW}, \mathrm{NICP}-708$ MW, which characterizes Irkutsk as the city with a high share of renewable energy sources. The electric power generated at the Irkutsk HPP covers the city's demands and ensures the functioning of large enterprises in the nearest populated areas: the Irkutsk aluminum smelter (Shelekhov town) and Irkutsk aircraft plant, which is currently increasing its production capacities. On the whole, the industry share in energy consumption of the city reaches $66 \%$. The rest of the electric power covers population needs. The main consumers of thermal energy produced by the NICP and municipal and departmental boiler houses are the population and social infrastructure.

In 2018 there were 89 boiler houses in the city, of which 57 used coal, 17 used liquid fuel (primarily fuel oil), and 15 were electric boiler houses. One boiler house burns fuelwood, i.e., sawdust. The city has no renewable energy sources for large-scale thermal energy production. Electric boiler houses and a boiler house running on fuelwood are not considered in assessing the $\mathrm{CO} 2$ emissions from boiler houses, and only coal and fuel oilfired boiler plants will be analyzed further.

To calculate the $\mathrm{CO} 2$ emissions from energy facilities (boiler houses on fossil fuel and the NICP) in Irkutsk, fuel consumption was analyzed for 1990, 2015, and 2018.

\section{A. Fuel consumption by energy facilities in the city of Irkutsk}

The consumption of fuel in 2015 and 2018, given its types, was determined using the data of heat supply schemes of Irkutsk for different years of their updating $[24,25]$, the State report on the protection of Lake Baikal [26], and the data of technical specifications of heat sources of the municipality of Irkutsk [27]. Brown coal is the primary fuel for thermal energy facilities of the city, Table 2 . 
Table 3. Calculated co2 emission from energy facilities in irkutsk city, thousand tons/year.

\begin{tabular}{lccc}
\hline \hline \multirow{2}{*}{ Energy facility } & \multicolumn{3}{c}{ Year } \\
\cline { 2 - 4 } & 1990 & 2015 & 2018 \\
\hline NICP & 3058.4 & 3641.7 & 3910.9 \\
\hline Boiler houses & 1770.2 & 1056.6 & 939.3 \\
\hline Total & 4828.5 & 4698.4 & 4850.1 \\
\hline \hline
\end{tabular}

The data on the amount of fuel burnt by the Irkutsk boiler plants and the NICP in 1990 are taken from the 1995 and 1999 official letters of the JSC "Irkutskenergo".

At present, the NICP burns primarily brown coal imported from the Kansk-Achinsk basin. Boiler houses use coal from local deposits of the Irkutsk region: brown coals and, in small amounts, hard coal.

For the considered period, the total fuel consumption (coal and fuel oil) by all energy facilities of the city is estimated at 1.6-1.7 million tce per year.

The major fuel consumer among the energy facilities is the NICP, with its share in the fuel consumption structure ranging from 62 to $80 \%$ in different years, Figure 1 .

As seen from Figure 1, the share of boiler houses in the total fuel consumption declined almost twice (from $38 \%$ in 1990 to $20 \%$ in 2018 ) with a significant increase in the share of NICP.

In the total fuel consumption structure, the fuel oil share gradually decreases from $12.2 \%$ in 1990 to $5 \%$ in 2018 , i.e., by 2.5 times, Figure 2 .

B. Assessment of carbon dioxide emissions from energy facilities in the city of Irkutsk

The calculations of carbon dioxide emissions from energy facilities with stationary fuel combustion are based on Order No. 300 of June 15, 2015 [28]. It is worth noting that greenhouse gases emitted by this category of sources includes only $\mathrm{CO}_{2}$ emissions due to the combustion of all liquid and hard fuel types used at boiler units to produce heat and/or electricity. Methane (CH4) and nitrogen oxide (N2O) emissions, which are potentially likely during stationary fuel combustion, are not considered.

The calculation results for carbon dioxide emissions from energy facilities of Irkutsk city are presented in Table 3.

The calculations show that the amount of $\mathrm{CO} 2$ from the city's energy facilities in different periods is 4.7 (2015) to 4.9 million tons (2018). The emissions of 2018 exceed those of the so-called reference year of 1990 by 21.6 thousand tons. Whereas according to the plans of the Russian Government, the emissions in 2020 must be equal to $75 \%$ of the 1990 level, i.e., no more than 3.6 million tons for Irkutsk city.

The thermal power plant (Novo-Irkutsk cogeneration plant) is the main contributor to $\mathrm{CO}_{2}$ emissions, with its share in the total carbon dioxide emissions increased from $63 \%$ to $80 \%$ in 2018 , compared to 1990 (Fig. 3).
Correspondingly, the contribution of boiler houses to the total CO2 emissions from energy facilities in Irkutsk city reduced from $37 \%$ in 1990 to $19 \%$ in 2018 .

A decrease in coal consumption by boiler houses and the replacement of some of them with one large-scale energy source, i.e., the Novo-Irkutsk cogeneration plant, led to an increase in the plant fuel consumption. In turn, carbon dioxide emission from the NICP increased by $26 \%$ against the 1990 level.

The lowest-carbon energy facilities are electric boiler houses. However, their number has not changed over the period under review (15 electric boiler houses in 2018 [25]). Moreover, future measures to improve heat supply to consumers in Irkutsk city do not include any plans for increasing the number of electric boiler houses and sources using renewable energy.

Although the regional energy companies make their efforts to implement the program to close economically and environmentally ineffective small-capacity boiler houses and connect heat consumers to the main source in the city, i.e., the NICP, the issue of reducing carbon dioxide emissions is unlikely to be resolved. In this regard, measures are necessary to reduce (save) fuel consumption at all energy facilities of the city, including the NICP.

\section{CONCLUSION}

The study provides a comparative analysis of the estimated carbon dioxide emissions from energy facilities in Irkutsk in 1990 and 2018. It is a starting stage in creating a city with a low carbon status, i.e., a city with low carbon dioxide emissions. Currently, emissions from energy facilities being the primary sources of $\mathrm{CO}_{2}$ in the city, are estimated at 4.9 million tons per year. These emissions have already exceeded the level of 1990 by 26 thousand tons. The set goals ( $75 \%$ of the 1990 level) can be achieved by reducing carbon dioxide emissions by at least 1.3 million tons.

With the existing energy infrastructure, Irkutsk has the potential to reduce carbon dioxide emissions. It can be implemented by cutting down fuel consumption through the adoption of innovative combustion technologies, the use of available coal-grading technology, and the increase in the number of electric boiler houses.

Modernization of the Irkutsk hydropower plant through the replacement of hydraulic units with expired service life by new ones will contribute to the energy efficiency enhancement in the near future, which will increase the plant's capacity by $20 \%$. Thus, it will be possible to additionally generate up to 200 million $\mathrm{kWh}$ of electricity per year, using the same amount of water as before the reconstruction.

The low carbon development of the city will largely depend on the development plans of Irkutsk city in the future. The question of whether Irkutsk will be a low carbon city is complicated as it requires answers to many 
sub-questions related to the development of a healthy urban environment. It is necessary to organize constant and continuous metering of energy consumption, to establish an energy conservation service, which will enable both individual enterprises and the entire city to significantly save energy resources.

Conversion of the city's energy facilities to gas can be one of the essential and realistically achievable measures. The use of natural gas as a fuel in the boiler houses and the cogeneration plant of the city will reduce carbon dioxide emissions more than twice against the 2018 level. Moreover, there is the Kovykta gas condensate field prepared for large-scale production in the Irkutsk region. Coordinated actions of the city and regional authorities will make it possible to convert consumers to gas not only in the cities and towns of the Irkutsk region but also in the neighboring regions.

Special attention should be paid to the transport segment, both public and personal means of transportation. Given that the city has the lowest electricity tariff in Russia, this fact should become the main stimulus for the development of electric transport.

With such a tariff policy pursued, it is also possible to carry out a gradual transition of private households to electric heating instead of the stove and often coal heating.

Wind generators and solar panels are represented by single instances (in the private sector) in Irkutsk city. The prospects for the development of renewable energy sources are limited, first of all, by the low cost of electricity. The successful use of renewable energy sources in the city in general seems unlikely without a policy focused on their support at the municipal, regional and federal levels.

Thus, to reduce carbon dioxide emissions in Irkutsk city, it is necessary to formulate a comprehensive program of carbon-free development, which should reflect not only the stages of a gradual transition to low carbon technologies but also a list of dedicated measures for specific types of economic activity. This issue must be addressed comprehensively in both the city energy sector and the entire infrastructure, from urban development to enterprises related to life support and fulfillment of various needs of citizens.

\section{ACKNOWLEDGMENTS}

The research was carried out under the State Assignment Project of the Fundamental Research Program of Russian Federation 2021-2030 (FWEU-2021-0004 № AAAA-A21-121012090010-7).

\section{REFERENCES}

[1] Climatically neutral cities. UN Economic Commission for Europe, Geneva, Switzerland, 2011, 116 pp. (in Russian).

[2] S. Arrhenius, "On the influence of carbonic acid in the air upon the temperature of the Earth," The Astronomical Society of the Pacific, Vol 9, No 54, pp 14-24, 1897. Available at: https://doi.org/10.1086/121158. (accessed 05.02.2021)
[3] J.T. Houghton, Y. Ding, D.J. Griggs, et al., "Climate change 2001: the scientific basis", The Press Syndicate of the University of Cambridge, 2001.

[4] Intergovernmental Panel of Climate Change, "Climate change 2014: mitigation of climate change", Cambridge University Press, Vol. 3, 2005.

[5] K.Ya. Kondratiev, V.F. Krapivin, "Modeling the global carbon cycle," Moscow, Russia, FIZMATLIT, 2004, 336 p. (in Russian).

[6] L.S. Kartunova, "Climate changes, causes and effects," Science, education and culture, No 1 (25), Moscow, Russia, 2018. Available at: https://cyberleninka.ru/ article/n/izmeneniya-klimata-prichiny-i-posledstviya/ viewer (accessed 05.02.2021) (in Russian).

[7] N.V. Petrov, "The clue to understanding the mechanism of global climate change of the planet and its long-term forecast," Academy of Trinitarianism, El No 77-6567, publ.26667, Moscow, Russia, 2020. Available at: http://www.trinitas.ru/rus/doc/0016/001h/00164494. $\underline{\mathrm{htm}}$ (accessed 15.02.2021) (in Russian).

[8] L.V. Bondarenko, O.V. Maslova, A.V. Belkina, K.V. Sukhareva, "Global climate change and its effects," Bulletin of the Plekhanov Russian University of Economics, no (2), p. 84-93, 2018. Available at: https://doi.org/10.21686/2413-2829-2018-2-84-93 (accessed 02.15.2021) (in Russian).

[9] Yu.G. Peshcherov, G.I. Peshcherov, "Focused anthropogenic influence on climate as a threat to vital activity of human society," Bulletin of Eurasian Science, No 2, 2018. https://esj.today/ PDF/89NZVN218.pdf (Free access) Available at: https://cyberleninka.ru/article/n/tselenapravlennoeantropogennoe-vliyanie-na-klimat-kak-ugrozazhiznedeyatelnosti-chelovecheskogo-obschestva/ viewer (accessed 02.05.2021) (in Russian).

[10] The environment of Europe. State and prospects 2015. Synthesis report, European Environment Agency, EEA, Copenhagen, 2015, 199 p. (in Russian).

[11] UN Framework Convention on Climate Change, as of May 9, 1992, UN Site, 2021. Available at: https:// www.un.org/ru/contact-us/index.html. (accessed 05.02.2021) (in Russian)

[12] What is the Kyoto Protocol? United Nations Framework Convention on Climate Change, UN Site, 2021. Available at: https://unfccc.int/ru/kyoto protocol (accessed 26.02.2021) (in Russian).

[13] The Paris Agreement, 2015, UN Site. Available at: https://unfccc.int/process-and-meetings/the-parisagreement/the-paris-agreement (accessed 26.02.2021) (in Russian).

[14] Materials of the North-Asian International Conference “NICE'for Economic Development", Niigata, Japan, 3-rd Stage "Japan-Russia Energy and Environment Dialogue - the Paris Agreement and Energy Security in Northeast Asia," 2021, Available at: https://www. erina.or.jp/en/activities/seminars/nice/2021nice/3rdstage/ (accessed 26.02.2021)

[15] M. Bui, C.S. Adjiman, A. Bardow, E.J. Anthony, A. 
Boston, S. Brown, P.S. Fennell, S. Fuss, A. Galindo, L.A. Hackett, "Carbon capture and storage (CCS): the way forward," JP, 2018.

[16] B. Metz, O. Davidson, H. C. de Coninck, M. Loos, and L.A. Meyer (eds.), "IPCC special report on Carbon Dioxide Capture and Storage," Cambridge University Press, Prepared by working group III of the Intergovernmental Panel on Climate Change, Cambridge, United Kingdom and New York, NY, USA, 2005.

[17] Ten breakthrough ideas in the energy sector for the next ten years, Association "Global energy," 2020, 106 p. (in Russian).

[18] V.O. Kindra, A.N. Rogalev, N.D. Rogalev, "The oxyfuel technologies of electricity generation with zero emissions of harmful substances into the atmosphere," Proc. of the International Scientific Conference of Young Scientists and Experts "Ecology of energy-2017”, Moscow, Russia, Publishing House of MEI, 2017, pp.110-113.

[19] Net Zero: The UK's contribution to stopping global warming, The Committee on Climate Change, 2019.

[20] Methodologicalguidelines and guidance of quantitative determination of volumes of greenhouse gas emissions by the organizations undertaking economic and other activities in the Russian Federation. Approved by the Order of the Ministry of Natural Resources of Russia of 30.06.2015. Moscow, Russia, 2015. Available at: http://sro150.ru/metodiki/371-metodika-raschetavybrosov-parnikovykh-gazov (accessed 26.02.2021) (in Russian).

[21] Regulation of the RF Government No. 504-r of 02.04 .2014 (ed. 17.06.2016) "On approval of the action plan to ensure the reduction of greenhouse gas emission volumes by 2020”. Moscow, Russia, 2016. Available at: https://legalacts.ru/doc/rasporjazheniepravitelstva-rf-ot-02042014-n-504-r/ (accessed 26.02.2021) (in Russian).

[22] The Federal Law No. 34-FZ of 04.11.1994 "On ratification of the UN Framework on Climate Change." Moscow, Russia, 1994. Available at: https:// legalacts.ru/doc/federalnyi-zakon-ot-04111994-n-34fz-o/ (accessed 26.02.2021) (in Russian).

[23] Framework Convention on Climate Change, The official site of the United Nations Organization. Available at: http://unfccc.int/ (accessed 26.02.2021) (in Russian).

[24] The heat supply scheme of the city of Irkutsk up to 2031 (updating for 2018). Irkutsk, Russia, 2019. Available at: https://admirk.ru/Pages/search.aspx?k=схема $\% 20$ теплоснабжения \%20г.\%20иркутск\%20до\%20 2031\%20г (accessed 15.09. 2020) (in Russian).

[25] The heat supply scheme of the city of Irkutsk up to 2033 (updating for 2020). Irkutsk, Russia, 2020. Available at: https://admirk.ru/Pages/generalniy-plan-goroda. aspx (accessed 15.09. 2020) (in Russian).

[26] The State report "On the state of Lake Baikal and measures on its protection in 2017," Irkutsk, ANO
“CC Expert,” Russia, 2018, 340 p. (in Russian).

[27] The Passport of the housing and communal services of MF of Irkutsk as of 1.01.2015, Irkutsk: RGD “Analytic operating-dispatching department of the housing and communal services of the Irkutsk region," Russia, 2015. (in Russian).

[28] The Order No. 300 of the Ministry of Natural Resources of Russia of 30.6.2015 "On approval of methodological guidelines and guidance of quantitative determination of volumes of greenhouse gas emissions by the organizations undertaking economic and other activities in the Russian Federation." Moscow, Russia, 2015. Available at: https://www.rosteplo.ru/Npb files/npb shablon. php?id=1740 (accessed 20.07.2020) (in Russian).

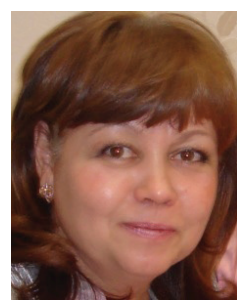

Elena Maysyuk Ph.D. in economics (2002), Senior Researcher of the Laboratory of Energy Supply to Offgrid Consumers, Melentiev Energy Systems Institute SB RAS, Irkutsk.

She graduated from the Energy faculty of the Irkutsk Polytechnic Institute with a major in Heat power plants (1989).

Her research area includes environmental issues of energy systems development in East Siberia and the Far East.

She authored and co-authored more than 85 publications, including chapters and sections in 20 collective monographs. 